\title{
Trabajo SOCIAL Y COMPLEJOS IDEOLÓGICOS. ClaVes Té́ricas PARA PENSAR loS PROCESOS DE INTERVENCIÓN PROFESIONAL
}

\author{
SOCLAL WORK AND IDEOLOGICAL COMPLEXITIES. \\ THEORETICAL ADVISES TO THINK OVER THE \\ PROFESSIONAL INTERVENTION PROCESSES.
}

\author{
Por: Sergio Daniel Gianna
}

Recibido 15 de diciembre 2013. Aprobado: 16 de marzo 2014

Estudiante del doctorado en Ciencias Sociales de la Universidad de Buenos Aires. Miembro del comité académico de la Revista Plaza Pública. Docente Universidad Nacional de la Plata.

\begin{abstract}
RESUMEN
Este trabajo presenta algunas reflexiones en torno a la relación entre el Trabajo Social, la categoría trabajo y los complejos ideológicos. Mediante el pensamiento de Georg Lukács, se busca reflexionar sobre el trabajo en cuanto actividad fundante del ser social y su distinción con los complejos sociales, cuya finalidad es actuar sobre las relaciones sociales. A partir de estos debates, se busca comprender por qué el Trabajo Social es un complejo ideológico y cómo mediante la aprehensión de sus particularidades, es posible desarrollar posiciones teleológicas que apunten a la construcción de estrategias de intervención profesional que superen la inmediatez y las meras demandas institucionales.
\end{abstract}

Palabras clave: Trabajo social, complejo ideológico, intervención profesional, teleología.

\begin{abstract}
This work present some reflections about the relationship between Social Work, job category and ideological complexities. Through the judgment of Georg Lukács, we seek to reflect about work as a foundational activity of social being and its distinction with social complexities, which aim to act on social relationships. As from these discussions, the intention is to understand why Social Work is a ideological complexity and how, through the apprehension of its peculiarities, teleological attitudes aiming to build professional intervention strategies overcoming promptness and the mere institutional claims may be developed.
\end{abstract}

Key words: Social Work - Ideological complexes - Professional intervention - Teleology .

\section{Presentación}

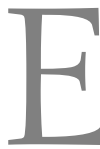

l artículo presenta algunas reflexiones teóricas en torno a la naturaleza del Trabajo Social como profesión a partir del tratamiento de algunas de las categorías que Lukács desarrolla en su obra de madurez, sobre todo, en la Ontología del ser social, donde se abordan algunos de los complejos esenciales de la sociabilidad humana: el trabajo, los complejos sociales, las posiciones teleológicas y la ideología. Mediante estos elementos se pretende alcanzar algunas determinaciones esenciales respecto a los procesos de intervención profesional de los trabajadores sociales. 


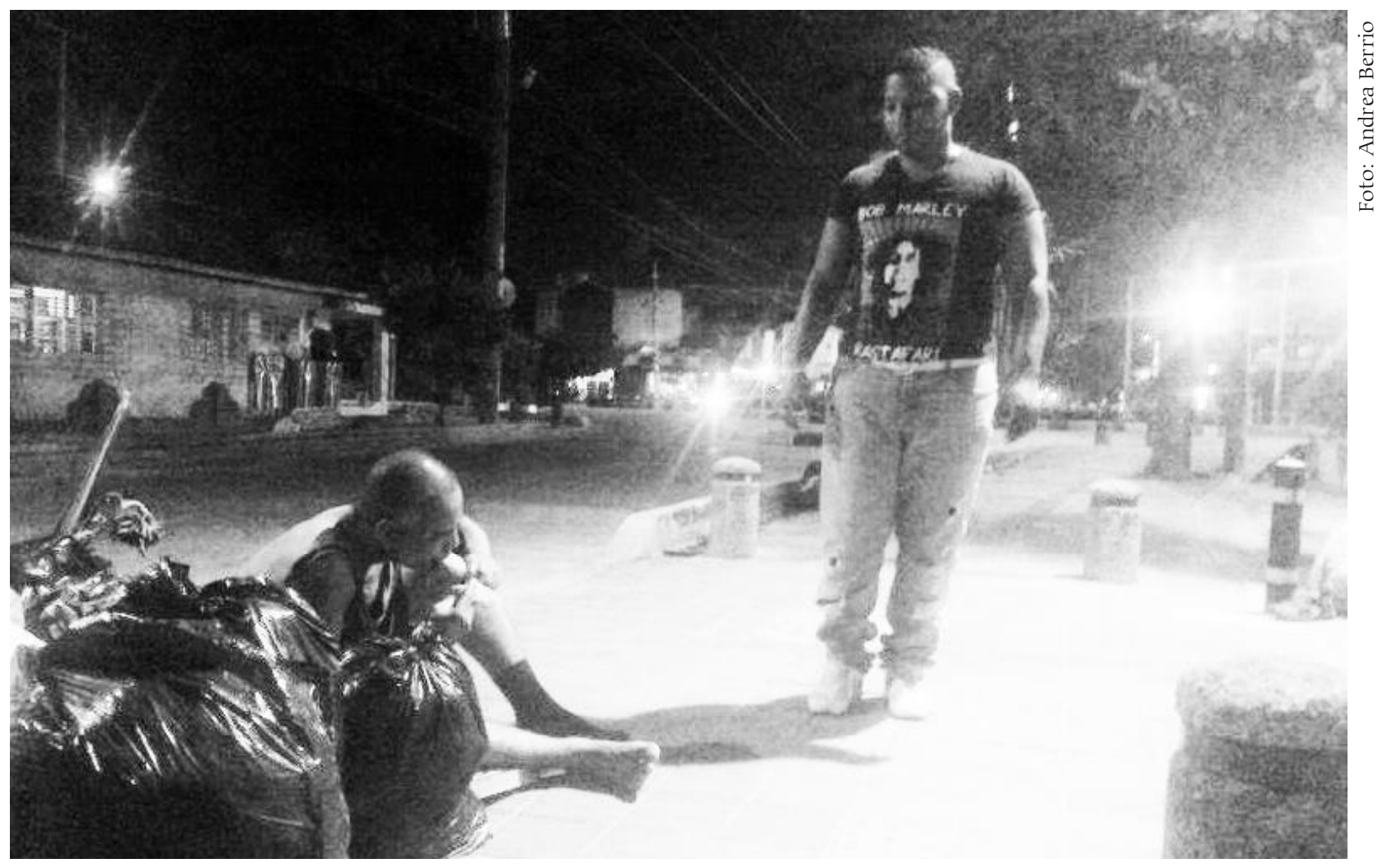

Para organizar la exposición, en un primer momento, se presentarán algunos aspectos fundamentales de la categoría trabajo como modelo de toda praxis humana, como posición teleológica primaria que, para Marx y Lukács, cumple una función social bien precisa en el proceso de producción y reproducción social, pese a que esta adquiere diversas formas a lo largo de la historia.

En un segundo momento se analiza como la sociabilidad humana, al desarrollarse intensiva y extensivamente, da origen a otras formas de praxis social, en cuanto posiciones teleológicas secundarias, que además de poseer ciertos rasgos universales y comunes con la categoría trabajo, estos no dejan de distinguirse y adquirir ciertas particularidades al buscar actuar sobre las relaciones sociales. Estas formas de praxis sociales, tendrán una vinculación directa con la categoría ideología.

Finalmente, en un tercer momento, se introducirán algunos aspectos que permiten polemizar con aquellas visiones que conciben al Trabajo Social como un proceso de trabajo y cómo la profesión vista como complejo social ideológico contribuye a pensar más concretamente los procesos de intervención y la construcción de estrategias de actuación profesional. 


\section{La categoría trabajo como modelo de toda praxis social}

T os planteos teóricos de Lukács (2004) acerca de la categoría trabajo se fundamentan en un supuesto ontológico esencial: para qué existe la Jhistoria humana, esto es, la génesis y el desarrollo del género humano, esta debe estar en condiciones de producir aquellos medios productivos y medios de consumo que permitan, mediante un proceso de transformación de la naturaleza, satisfacer aquellas necesidades humanas indispensables paras la reproducción de los individuos y de la sociedad como un todo. En torno a este supuesto, Marx explícitamente señala que el trabajo es "[ ...] apropiación natural para las necesidades humanas, condición general del metabolismo entre el hombre y la naturaleza, eterna condición natural de la vida humana y por tanto independiente de toda forma de esa vida, y común, por el contrario, a todas sus formas de sociedad" (2002: 223).

Esta base indispensable para la vida humana, que crea riqueza social mediante la transformación de la naturaleza, no debe incurrir en el error de concebir que ésta se encuentra regida por leyes del orden de lo natural o que la legalidad social se homologa a la legalidad de la naturaleza, por el contrario, su sentido es destacar un elemento que a menudo es olvidado por las ciencias sociales: sin los productos del trabajo no hay reproducción biológica del cuerpo humano $y$, por ende, no existen condiciones para la historia social y humana.

Para Lukács (2004) existe una dialéctica de la continuidad y la discontinuidad en el ser social: si los hombres surgen de la naturaleza orgánica, estos poseen ciertos atributos biológicos que heredan de dicha esfera del ser, pero, al mismo tiempo, predominan elementos de discontinuidad que lo diferencian de la naturaleza orgánica, ya que los aspectos sociales y el desarrollo de la capacidad humana inherente al trabajo adquieren preeminencia en la vida humana.

Esto último se expresa con claridad en que tanto la esfera de la naturaleza orgánica, en particular en los animales, como en el mundo de los hombres, la reproducción es una determinación común a ambas, pero el modo en que se realiza la misma difiere ampliamente entre sí. Los primeros actúan de modo instintivo sobre el medio, interactuando con el ambiente mediante "respuestas" repetitivas e inmediatas que son aprendidas mediante un proceso de aprendizaje que se realiza de una vez para siempre, mientras que el hombre antepone en su conciencia un conjunto de posibles y múltiples respuestas que luego serán objetivadas en la realidad. Es decir, el hombre construye respuestas medidas a sus necesidades, ya que la misma 
presupone una pregunta que se inicia con una necesidad que tiene por base una realidad natural y/o social (Lukács, 1981).

Según Marx "Al consumarse el proceso de trabajo surge un resultado que antes del comienzo de aquél ya existía en la imaginación del obrero, o sea idealmente" (2002: 216). Esto significa que el trabajo es antecedido por una posición teleológica que establece, a partir de una necesidad, una finalidad para el accionar humano y define cuales son los medios más acordes para alcanzarla, produciendo una nueva objetividad, un valor de uso, en el que continúan presentes sus determinaciones naturales, sus fundamentos ontológiconaturales, pero adopta formas aptas para satisfacer una necesidad humana. En otros términos, La teleología o previa ideación refiere a la construcción, en el plano de la conciencia, de los posibles resultados de una acción.

Así, todo acto de trabajo se funda en una posición teleológica, en un momento ideal, que antecede y dirige la acción, actuando sobre la realidad para transformarla y buscando que una causalidad dada -concebida como un movimiento autónomo que se basa a sí mismo y sin finalidad alguna- se vuelva una causalidad puesta, causalidad que es sometida al accionar humano y sus finalidades, generando una nueva objetividad. Para Lukács (2004) lo específico del mundo de los hombres es que este se constituye a partir de una unidad entre teleología y causalidad, entre las posiciones teleológicas de los individuos y la transformación de la causalidad dada de la naturaleza por una causalidad puesta.

Retomando los planteos de Aristóteles y Hartmann, Lukács (2004) señala que el trabajo, como posición teleológica, posee dos elementos constitutivos: el acto de pensar y de producir, siendo el primero compuesto por la determinación de la finalidad y la investigación de los medios, mientras que el segundo alude al proceso de objetivación, del cual se hará referencia más adelante.

La posición del fin del trabajo tiene su origen en una necesidad humana, la cual, para poder realizarse requiere de una investigación de los medios, esto es, debe aprehender las cualidades y determinaciones de aquellos objetos y cadenas causales que son esenciales para la consecución de la finalidad. Este último aspecto permite al hombre no solo conocer las propiedades y cualidades inherentes a la realidad, sino que también permite captar potencialidades y posibilidades que solo existen de manera latente en la naturaleza y que solo pueden efectivizarse mediante el accionar consiente y voluntario de los hombres (Lukács, 2004). 
La investigación de los medios no solo conduce a conocer las propiedades y determinaciones de los objetos de trabajo y a crear aquellos instrumentos que son antepuestos entre él y el objeto para transformarlo, sino que también se produce un reflejo de la realidad, en la que el sujeto reproduce en la conciencia la realidad y aquella porción de la naturaleza que es externa al hombre y que intenta transformar. Cabe destacar que el reflejo no es un acto mecánico que el hombre realiza, por el contrario, supone un rol activo del mismo y de su subjetividad, alcanzando, por un lado, siempre un conocimiento aproximativo de la realidad, susceptible de ampliación y desarrollo producto del carácter más complejo, diverso y rico de la propia realidad. Dicho conocimiento puede estar acompañado de falsas representaciones y visiones del mundo, que no impiden que el hombre conozca la realidad para transformarlo, pero las explicaciones acerca del origen y destino de los propios hombres resulta falso, como en el caso de las representaciones mitológicas y religiosas. Por otro lado, la posición teleológica y el reflejo son apenas un momento ideal, del cual, es el momento real el que ocupa el momento predominante, ya que la validez de estos solo pueden ser comprobados mediante la puesta en práctica del trabajo, donde la realización exitosa o el fracaso de la misma dependerá de la capacidad de aprensión de aquella porción de la realidad que se busca transformar.

De este modo, la posición teleológica permite orientar el pasaje de la posibilidad, en cuanto proyecto ideal que existe en la conciencia de un individuo, a la objetivación, al momento real, que enfrenta al individuo al proceso de transformar la causalidad dada en una causalidad puesta, debiendo optar por una cadena de alternativas que le permitan alcanzar la consecución de la finalidad planteada. Tanto el momento ideal como el momento real son una unidad que es separada con fines analíticos, siendo la teleología como la objetivación orientados por un deber ser que coloca en el accionar humano el horizonte del futuro, siendo todas las acciones relacionadas con el trabajo guiadas por un resultado que ya está presente en la conciencia de los individuos.

Mediante la objetivación del trabajo la realidad comienza a ser transformada por el propio hombre, apareciendo un conjunto de valores de uso que antes apenas existían como posibilidad en la naturaleza. Como advierte Marx, "El proceso se extingue en el producto. Su producto es un valor de uso, un material de la naturaleza adaptado a las necesidades humanas mediante un cambio de forma. El trabajo se ha amalgamado a su objeto. Se ha objetivado, y el objeto ha sido elaborado. Lo que en el trabajador aparecía bajo la forma de movimiento, aparece ahora en el producto como atributo en reposo, bajo la 
forma de ser" (2002: 219). Es decir, la objetivación alude a la transformación de la realidad externa al sujeto según el sentido planteado por la teleología.

La transformación de la naturaleza también repercute y tiene una acción de retorno sobre el propio individuo, ya que "al operar por medio de ese movimiento sobre la naturaleza exterior a él y transformarla, transforma a la vez su propia naturaleza" (Marx, 2002: 215-216). A este proceso Lukács (2004) se referirá como la exteriorización, que en el acto del trabajo se expresa en el control que el individuo adquiere sobre sí mismo y su cuerpo, permitiéndole evaluar y corregir aquellos actos singulares concatenados al acto laboral. No obstante, la exteriorización no se limita a ello, ya que el individuo, con el proceso de trabajo, adquiere nuevas habilidades, aptitudes que antes no poseía y obtiene nuevos conocimientos sobre la realidad que produce entre lo conocido y los desconocido, ya que con el mismo acto de conocer no solo se aumentan las certezas y se profundizan las parcelas de la realidad conocidas, sino que también se introducen nuevas preguntas que amplían el campo de lo desconocido. Este desarrollo de los aspectos subjetivos de la individualidad conduce a personalidades humanas más ricas y complejas en cada momento histórico.

Hasta aquí, puede sintetizarse el excurso planteado en torno al trabajo diciendo que este es: a) el resultado de un momento ideal motorizado por la conciencia, dejando de ser un epifenómeno de los aspectos biológicos de los animales, que mediante una necesidad, establece las finalidades y los medios del accionar humano; b) existen múltiples formas de responder a una misma necesidad, construyéndose respuestas de carácter mediado; c) la objetivación genera una nueva situación individual y genérico-social que supera la reproducción rectilínea y siempre igual de la naturaleza orgánica. Lukács (1981) advertirá que la reproducción simple del trabajo contiene en sí las condiciones para la reproducción ampliada, ya que el mismo no solo permite satisfacer una necesidad concreta, sino que también permite generalizar aquellos conocimientos y productos del trabajo y aplicarlos a nuevas necesidades y procesos laborales.

Según Marx "Los elementos simples del proceso laboral son la actividad orientada a un fin o sea el trabajo mismo, su objeto y su medio" (2002: 216), siendo estos, pese a sus mutaciones históricas y las formas concretas que estos adoptan, los aspectos centrales del trabajo como categoría. 
Para concluir, resta destacar dos elementos importantes relacionados a la categoría trabajo. El primero se refiere a que el proceso laboral desempeña una función social muy específica dentro de la sociabilidad humana, ya que este "[...] contiene un proceso entre la actividad humana y la naturaleza: sus actos están orientados a la transformación de objetos naturales en valores de uso" (Lukács, 2004: 103). El trabajo es una posición teleológica primaria estrictamente ligada al proceso de transformación de la naturaleza y a la creación de la riqueza social en un momento histórico determinado. En segundo término, si el trabajo es la actividad fundante del ser social, sin la cual no sería posible la reproducción de la vida humana, esto no supone que la sociabilidad humana se reduzca a esta, sino que existe una "identidad de la identidad de la no identidad" entre el trabajo y la existencia de otras formas de praxis humana.

La posición que Lukács (2004) asume respecto a la sociabilidad humana, como complejo de complejos, además de contener la economía, como complejo ontológico donde se desarrollan los diversos actos de trabajo existentes en una sociedad, producen otras formas de praxis social que, adquiriendo formas institucionales o espontáneas, no actúan de modo directo en el intercambio de la sociedad con la naturaleza, sino que su finalidad y su objeto son los individuos y las relaciones sociales.

A continuación se presentarán algunos de los aspectos que particularizan a dichas formas de praxis social, en cuanto posiciones teleológicas secundarias, y cómo este planteo conduce a superar aquellas visiones del marxismo, más próximas al positivismo, que reducen la sociabilidad humana a un factorialismo de causa y efecto donde la economía determina de forma unívoca y monocausal la superestructura jurídico-política.

\section{Las posiciones teleológicas secundarias como complejos ideológicos}

T Tasta aquí se ha intentado mostrar cómo, para Lukács (2004), el trabajo es una categoría esencial e ineliminable de la vida humana, dando lugar a un proceso de sociabilidad que, en su desarrollo, da origen a nuevos complejos y dimensiones que la vuelven más mediada y compleja. Es decir, el proceso de producción y reproducción es un complejo de complejos donde aparece un sistema de mediaciones que no se vincula de modo directo con la trasformación de la naturaleza por parte de la sociedad, haciendo que esta diversidad y multiplicación de momentos heterogéneos que la componen no rompa la unidad del ser social y su sociabilidad, por el 
contrario, la vuelve más rica y diversa con la incorporación de los mismos. En palabras de Lukács, "[...] si no podemos contraponer en términos metafísicos absolutos, sin escalas, la esfera económica a la superestructura, no podemos tampoco hablar que el complejos de las posiciones teleológicas entre el ser social es un conjunto uniforme, indiferenciado [...] queda claro que estas dos formas de ser, unidad entre sí por una infinidad de interacciones, constituyen una unidad dinámica, en las que las determinaciones concretas de su ser procesual, no obstante, se presentan muy diferentes" (1981: 364-365).

Esto, que hasta aquí parece algo excesivamente abstracto, refiere a lo que Marx y Engels (1959) llamaron el "retroceso de las barreras naturales", el cual, no solo expresa la creciente capacidad que han tenido los hombres de dominar y transformar el medio, en particular la naturaleza, sino que también refiere a que la sociabilidad humana, sus aspectos sociales, impregnan todos los poros de la vida social, apareciendo, además del trabajo como posición teleológica primaria, posiciones teleológicas secundarias que, de modo espontáneo o adquiriendo un cierto carácter institucional, tienen por finalidad actuar e incidir sobre la conciencia y la práctica de otros individuos, es decir, sobre sus posiciones teleológicas, de modo tal que objetiven con sus acciones determinadas alternativas y sean descartadas otras.

Si las posiciones teleológicas primarias objetivadas en los procesos de trabajo actúan sobre las cadenas causales de la naturaleza para producir valores de uso, las posiciones teleológicas secundarias actúan sobre los individuos, grupos y relaciones sociales, para regular, modificar o transformar las mismas. En palabras de Lukács: "El contenido esencial de la posición teleológica es [...] la tentativa para conseguir que un hombre (o un grupo de hombres) realice, por su parte, posiciones teleológicas concretas" (2004: 103).

Esta distinción inicial no debe opacar la existencia de dos rasgos generales entre las dos posiciones teleológicas. Ambas parten de un momento ideal, que proyecta las acciones y sus posibles consecuencias, determina los fines y los medios. En segundo término, una y otra requieren de un reflejo que, si bien poseen particularidades a partir del objeto que captan, sea capaz de alcanzar un conocimiento de las leyes tendenciales que la constituyen. En el caso de la posición teleológica primaria es posible suspender de forma más entera las valoraciones subjetivas que tienen los individuos, mientras que en las posiciones teleológicas secundarias esto se vuelve más complejo y dificultoso. 
Además de estos aspectos generales presente en toda posición teleológica, no debe dejarse de reconocer que existen ciertas particularidades entre las posiciones teleológicas primarias y secundarias, sobre todo, al mutar la materialidad o el objeto sobre el cual actúa. Para Marx, en el caso del trabajo, los objetos son aquellos elementos que preexisten en la naturaleza y se desligan de su conexión directa con la tierra, mientras que la materia prima "[... ya ha pasado por el filtro de un trabajo anterior [...]" (2002: 217). Estos rasgos específicos de los objetos y de la materia prima hacen que los medios de trabajo sean un intercesor entre el trabajador y el objeto de trabajo, el cual, valiéndose "[...] de las propiedades mecánicas, físicas y químicas de las cosas para hacerlas operar, conforme al objetivo que se ha fijado, como medios de acción sobre otras cosas" (Marx, 2002: 217). Tanto la materia prima como los instrumentos y medios de trabajo, que serán retomados en el apartado siguiente, se ligan estrictamente al proceso de trabajo que transforma, con el accionar humano, la naturaleza.

Es decir, las posiciones teleológicas primarias actúan sobre una materialidad que posee leyes regulares ligadas a la física, la química y la biología, mientras que las posiciones teleológicas secundarias intervienen en una materialidad distinta: las relaciones sociales y la conciencia y las prácticas que encarnan ciertos individuos.

Esto introduce modificaciones en la finalidad y en los medios a utilizar. Respecto al primero de ellos, Lukács señala que la posición teleológica primaria “[... está relacionada con objetos y procesos que, al ser puestos, se muestran totalmente indiferentes hacia el fin teleológico; mientras que aquellas posiciones que tienen por objeto suscitar en los hombres determinadas decisiones entre alternativas, actúan en un material que, de por sí, espontáneamente, tiende a decidir entre alternativas" (2004: 112). En referencia a los medios, Lukács advierte como estos cambian en las posiciones teleológicas, al señalar que pueden ir del "[...] uso directo de la violencia en la esclavitud y en los siervos de la gleba, hasta la manipulación de hoy" (1981: 338).

Estas posiciones teleológicas secundarias aparecen en una fase muy primitiva de la vida humana, ya que en el proceso de organizar el metabolismo social por parte de un grupo social ciertos individuos tienden a determinar con anterioridad cuáles son las funciones y roles que deben desempeñarse en el trabajo colectivo, distribuyendo las tareas y acciones a cumplimentarse. Esto genera una cooperación social, que "[...] está precedida de una posición teleológica que determina el carácter, el papel, la función, etc. De las posiciones 
individuales, ahora concretas y reales, orientadas a un objeto natural. El objeto de estas posición secundaria no es, pues, ya algo puramente natural, sino la conciencia de un grupo humano [...]" (Lukács, 2004: 104).

Para Lukács (1981) estas posiciones teleológicas secundarias tendrán una relación directa con la ideología, al considerarla como un instrumento del cual los individuos y grupos sociales adquieren conciencia de los conflictos sociales y actúan sobre ello. Esta concepción de las posiciones teleológicas secundarias y la ideología retoma el planteo de Marx de la Contribución a la crítica de la economía política, en la que señala que "Con la modificación del fundamento económico, todo ese edificio descomunal, se trastoca con mayor o menor rapidez. Al considerar esta clase de trastrocamientos, siempre es menester distinguir entre el trastrocamiento material de las condiciones económicas de producción [...] y las formas jurídicas, políticas, religiosas, artísticas o filosóficas, en suma, ideológicas, dentro de las cuales los hombres cobran conciencia de este conflicto y lo dirimen" (2004: 67).

A partir de esto, Lukács va a extender el planteo de Marx, inicialmente ligado a un momento esencialmente revolucionario, a las diversas situaciones y manifestaciones que ocurren en el cotidiano: "Creemos, por eso, estar autorizados a aplicar la esencia de la caracterización marxiana también a la cotidianeidad de la respectiva formación, y ver en las formas ideológicas los instrumentos por los cuales son concientizados y enfrentados también los problemas que ocupan tal cotidianeidad" (Lukács, 1981: 446).

La ideología, de este modo, es una elaboración ideal de la realidad que apunta a volver consciente y operativa la praxis de los hombres, actuando esta en una sociedad concreta y en un momento histórico determinado. Por ello, existe para Lukács (1981) una concepción amplia de ideología, que se manifiesta ya en estas fases iníciales de la sociabilidad humana, en la que existía un conjunto de normas y aptitudes sociales y colectivas que los individuos debían objetivar, aún cuando las mismas no eran impuestas a partir de relaciones de dominación y explotación.

Poniendo como ejemplo la cooperación para la caza en el período del paleolítico, Lukács (2004) muestra no solo que existen ciertos individuos que organizan el trabajo sin objetivarlo, sino que también estos determinan las funciones que los individuos deben desempeñar (bastidores y cazadores) y "[...] modos 
de actuar universalmente reconocidos para regular la cooperación y las expresiones de la vida a ella asociada [...]" (Lukács, 1981: 456). En ese sentido, la ideología es un complejo esencial de la sociabilidad humana.

Asimismo existe para Lukács una concepción restricta de ideología, que convierte a la misma en un instrumento de lucha social entre grupos y clases sociales. Esto "[...] presupone conflictos sociales, que en último análisis deben ser enfrentados [...] sobre el plano socio-económico, pero que en cualquier sociedad concreta producen para tal ámbito formas específicas: justamente las formas concretas de la respectiva ideología" (Lukács, 1981: 452). La concepción restricta de ideología se vincula con la aparición de sociedades de clases cuyos intereses en pugna buscan instituirse como interés general de una sociedad entera.

Los antagonismos sociales y la disputa de intereses entre grupos y clases sociales no solo se ligan a cierto desarrollo de la división del trabajo y a la forma de organizar el proceso de producción y reproducción social, sino también a la conformación de instrumentos ideológicos que permitan dirimirlos.

La ideología es una forma de conciencia que, sin ser absolutamente idéntica a la conciencia de la realidad, permite dirimir los conflictos sociales, ligándolos directamente con la praxis. La ideología en sociedades de clase no solo torna operativa la práctica social, sino que la hace de modo tal de responder a las necesidades de las clases sociales en disputa, volviendo a sus miembros conscientes de sus intereses y de los conflictos sociales.

La doble acepción de ideología que trabaja Lukács (1981) permite superar aquellas visiones que definen a la misma como "falsa conciencia", como si esta fuera un reflejo deformado de la realidad que impide la comprensión de los nexos causales existentes en la misma. Esta crítica, que se limita a los aspectos de orden gnoseológico, no concibe que muchas expresiones de "falsa conciencia" nunca se convirtieran en una ideología. Por ello, la ideología no solo, en el mayor de los casos, no soporta una crítica gnoseológica rigurosa, sino que inclusive ciertas teorías científicas pueden convertirse en ideología, ya que no es este aspecto el que las define como tal, sino su función social, esto es, "[...] tornarse vehículo teórico o práctico para combatir conflictos sociales" (Lukács, 1981: 449).

Es esta función social que desempeña la ideología la que lleva a que ciertas 
posiciones teleológicas secundarias se institucionalicen en complejos sociales ideológicos, con el fin de operacionalizar ciertas posiciones teleológicas en detrimento de otras e intervienendo de modo sistemático sobre los conflictos sociales existentes en una sociedad determinada.

Dichos complejos ideológicos actúan sobre una materialidad social, las relaciones sociales, para reproducirla o modificarla, permitiendo sostener aquella forma de organización social que hace posible la continuidad del modo en que está organizado el proceso de metabolismo social, esto es, la producción y reproducción social. Es decir, los complejos ideológicos no actúan de modo directo sobre el proceso de transformación de la naturaleza ni pueden confundirse con el trabajo. No obstante, "[...] el proceso de reproducción económica, a partir de un estadio determinado no podría funcionar, ni en el plano económico, si no se formasen campos de actividad no económica que tornasen posible el desarrollo de ese proceso en el plano del ser" (Lukács, 1981: 376-377).

Aquí solo puede destacarse, de modo muy genérico, dos complejos sociales que, por su función ideológica, abarcan un espectro de elementos comunes a otras posiciones teleológicas secundarias: por un lado, el derecho se constituye como complejo social ideológico para actuar sobre los conflictos cotidianos que derivan de la organización social. Si no es posible detenerse sobre su génesis histórica, puede resaltarse que este determina, de antemano, mediante una configuración normativa que conductas positivas y negativas los individuos pueden objetivar. Este ordenamiento jurídico no solo es instituido por el Estado, sino que también permite que un conjunto de individuos haga de este su ámbito de participación laboral en la división social y técnica del trabajo.

Estas cualidades hacen del derecho un complejo social restricto. Por otro lado, existen complejos sociales ideológicos de carácter puro, que si bien tienen fuertes grados de influencia sobre los individuos, estos no se materializan de modo directo en la práctica ni poseen un espacio institucional concreto. Estos complejos son la filosofía y el arte, los cuales, permiten iluminar los conflictos históricos de una época y los comprende en el marco del desarrollo del género humano y de la individualidad humana, generando una "imagen ontológica del universo y del mundo".

A partir de estos planteos, que analizan las particularidades de la categoría trabajo y de los complejos ideológicos, es posible avanzar en el análisis de la naturaleza del Trabajo Social, discutiendo si este, desde la obra de Lukács (2004) 


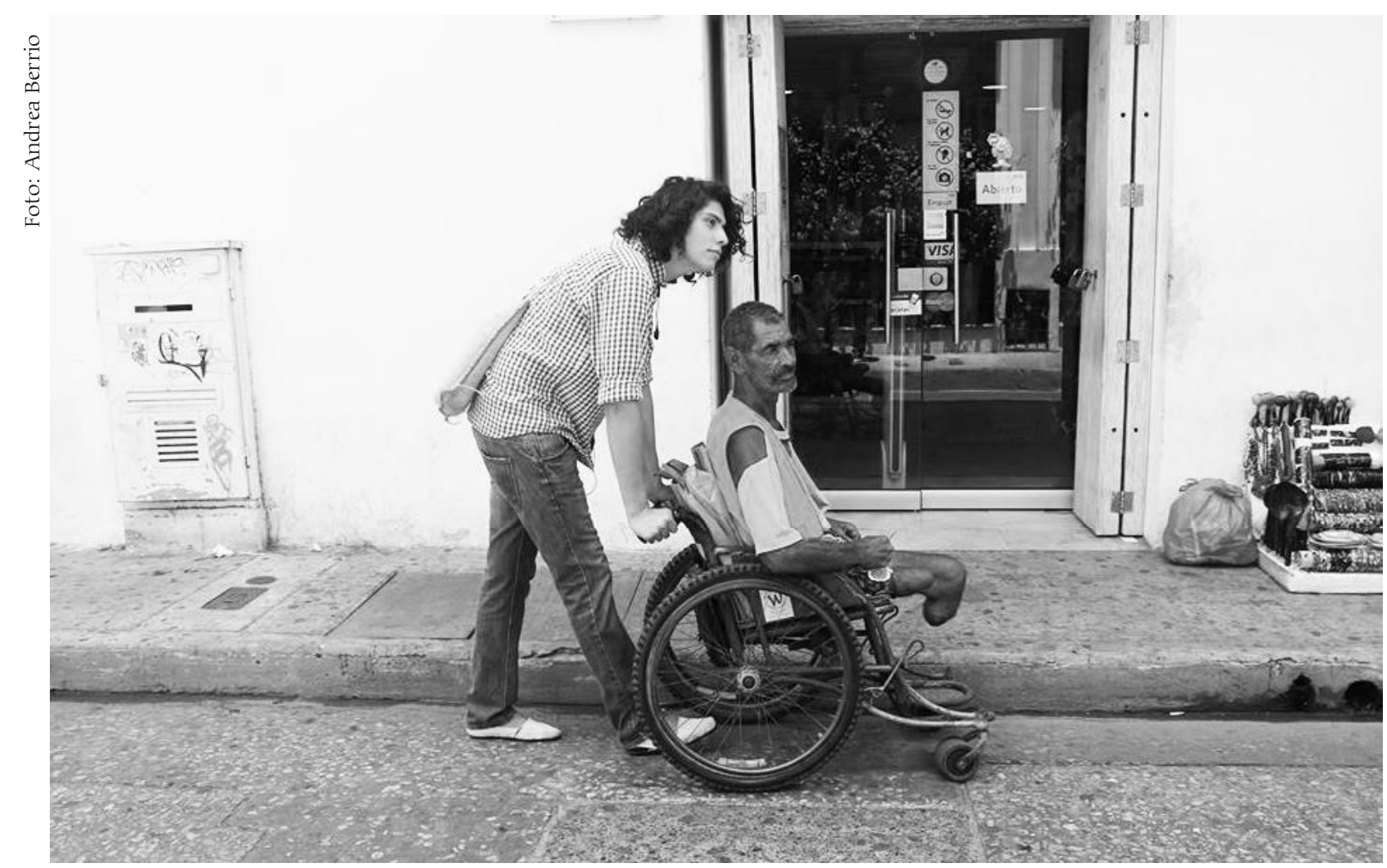

y Marx (2002), sería un proceso de trabajo o un complejo social ideológico y cómo esto es esencial para pensar los procesos de intervención profesional.

\section{La profesión Trabajo Social: ¿proceso de trabajo o complejo ideológico?}

os estudios que han abordado la génesis del Trabajo Social desde la
perspectiva histórico-critica muestran cómo la profesión, inserta en la
división social y técnica del trabajo en la fase monopólica del capitalismo, surge cuando el Estado comienza a desempeñar un abanico de funciones económicas y políticas y, entre ellas, aparecen las políticas sociales destinadas a abordar el conjunto de manifestaciones y expresiones de la "cuestión social", esto es, los problemas sociales que se derivan de la relación social general y antagónica de la sociabilidad capitalista: la relación entre capital y trabajo.

Esta inserción del Trabajo Social en la división social y técnica del trabajo ha llevado, a algunos autores (Iamamoto 1997, Netto 1997), ha considerar que esta vinculación homologa a la profesión, en una relación de identidad, con un proceso de trabajo, como si fuera una posición teleológica primaria que posee una materia prima y medios e instrumentos de trabajo. En otros términos, se plantea que al ocupar un lugar en la división del trabajo esto le atribuye a la profesión los rasgos constitutivos de las posiciones teleológicas primarias. Sintetizando los planteos de algunos de estos autores, en el caso de Iamamoto 
(2003), este plantea que debe dejarse de concebir a la intervención profesional como una práctica profesional y se la considere como un proceso de trabajo, el cual, como "cualquier proceso de trabajo implica una materia prima $\mathrm{u}$ objeto sobre el cual incide la acción del sujeto, o sea el propio trabajo que requiere de medios o instrumentos para que pueda ser efectuado" (2003: 80). Esto, lleva a concebir a la "cuestión social" como el objeto o materia prima del Trabajo Social y a los instrumentos y medios de trabajo como aquellos conocimientos que permiten comprender la realidad, las técnicas empleadas en la intervención y los recursos con los que dispone la profesión.

Por su parte, Karsz (2007) concibe al Trabajo Social como un proceso de producción, que se inicia con una materia prima y termina con un producto final. La materia prima del Trabajo Social, desde una fidelidad mecánica con Marx, alude a situaciones problemáticas que ya fueron producidas con anterioridad a la intervención y sobre la cuál el profesional debe aplicar sus medios de trabajo, siendo "[...] el conjunto de herramientas, dispositivos y referencias -manuales e intelectuales- necesarios para intervenir sobre la materia prima" (Karsz, 2007: 58). Junto a los medios opera la fuerza de trabajo, esto es, las capacidades y competencias teóricas, físicas e intelectuales de los profesionales. De todo esto se obtiene un producto final, el cual, "[...] resulta del empleo, por agentes cualificados, de unos medios de trabajo sobre una determinada materia prima. Utilizada a propósito del trabajo social, la denominación "producto" expresa que hay una fabricación en juego: entre el punto de partida y el punto de llegada se han introducido ciertas transformaciones" (Karsz, 2007: 73).

La breve alusión a la perspectiva de estos autores conducen a un triple error: el primero, que no conciben que "la división del trabajo comienza cuando las ocupaciones singulares se autonomizan en profesiones" (Lukács, 1981: 139). Es decir, la división social y técnica del trabajo surge cuando aparecen un conjunto de actividades sociales, entre ellas las profesiones, que se constituyen en espacios funcional-laborales para ciertos individuos y grupos sociales, pudiéndose dedicar a las mismas y obtener con ella aquellos productos del trabajo necesarios para la reproducción individual y social, sin que ellos mismos tengan que producirlas directamente. Es decir, esto presupone un grado de sociabilidad humana en la que hay miembros de la sociedad que pueden asumir ciertas especialidades que no tienen vinculación directa con la producción de valores de uso que derivan de la transformación de la naturaleza y, de este modo, objetivando posiciones teleológicas secundarias. 
De este modo, la aparición de estas profesiones de las que habla Lukács (1981), entre las que podría ubicarse al Trabajo Social, no significa que estas estén por fuera de la división social y técnica del trabajo, por el contrario, forman parte de la misma pero sin ser un proceso de trabajo: pudiendo tener algún grado de relación con la esfera ontológica de la economía, contribuyendo a que ésta se desenvuelva correctamente, pero sin ser confundida con una posición teleológica primaria.

Este primer error incurre en considerar que la necesidad de estos complejos sociales ideológicos, que objetivan posiciones teleológicas secundarias, puede ser homologada, en una relación de identidad, con las posiciones teleológicas primarias, por el mero hecho de que todas forman parte de la división social y técnica del trabajo. Por el contrario, esta última se compone de posiciones teleológicas primarias y secundarias. En términos de Lukács "Cuanto más se desarrolla el trabajo, y con ello la división del trabajo, tanto más autónomas se tornan las formas de las posiciones teleológicas de segundo tipo, y tanto más se pueden desarrollar en un complejo para sí mismo de la división del trabajo" (1981: 155).

En segundo término, esto induce a otro aspecto problemático, ya que la identidad planteada entre la categoría trabajo y las posiciones teleológicas secundarias terminan por cancelar sus aspectos distintivos y la función social que desempeñan cada una de estas: si el trabajo tiene por finalidad transformar la naturaleza para generar aquella riqueza social necesaria para la reproducción social, los complejos sociales ideológicos actúan en la preservación y/o transformación de las relaciones sociales existentes entre los hombres, es decir, "al trabajo cabe la producción de los medios de producción y subsistencia, a las otras formas de praxis caben las funciones preparatorias (las más diversas) indispensables a la realización de los actos de trabajo históricamente necesarios" (Lessa, 2007: 37).

Finalmente, en tercer término, estos planteos teóricos conducen a una forma de conocer la realidad que, muy próxima al positivismo, considera que los individuos y las relaciones sociales sobre las que interviene el Trabajo Social se constituyen en "cosas", muy semejantes a la legalidad de la naturaleza, que posee leyes naturales y sobre las cuales los individuos no pueden actuar para transformarla y apenas es posible modificar ciertas variables y aspectos de las mismas. 
Afirmar que la "cuestión social" es un objeto de trabajo o materia prima termina negando la existencia de distinciones entre la legalidad natural y social, entre la naturaleza orgánica y la sociabilidad y si bien este no es el planteo que los autores explicitan, estas son sus consecuencias teóricas llevadas al extremo, ya que se cosifican -se vuelven cosas- a los individuos y a las relaciones sociales y, a la inversa, las propiedades sociales deberían también existir en la legalidad de la naturaleza. Igualmente, este planteo tampoco arroja demasiadas luces en lo que refiere a cómo pensar el proceso de intervención profesional y las particularidades a las que se enfrenta el profesional cotidianamente.

De este modo, el Trabajo Social posee aquellas determinaciones universales de las posiciones teleológicas: objetiva una posición teleológica antecedida por un momento ideal; su materialidad tiene algún grado de relación mediata con la producción de bienes materiales, al actuar sobre aquellas capas de la sociedad -las clases subalternas- que producen la riqueza social, y obtiene un salario a cambio de la actividad profesional. Lo que la distingue de la categoría trabajo es justamente su función social: no participa de aquellas actividades destinadas a producir la base material de la sociedad y su materialidad no es natural, sino eminentemente social: las relaciones sociales propias de la sociabilidad capitalista (Lessa, 2007).

En síntesis, el Trabajo Social tanto por el lugar que ocupa en la división social y técnica del trabajo (contratado principalmente por el Estado, en cuanto instancia que no se vincula propiamente con la categoría trabajo, pero que contribuye a reproducir las relaciones sociales y a generar las condiciones objetivas y subjetivas para el funcionamiento del metabolismo social) como por el tipo de legalidad sobre el que interviene (de carácter social, actuando sobre los problemas sociales que derivan de la "cuestión social") hacen visible porque sería, desde la argumentación expuesta, una posición teleológica secundaria.

Desde esta óptica, el Trabajo Social sería una posición teleológica secundaria que desempeña una función de carácter ideológica, ya que actúa sobre los problemas sociales cuyo origen se encuentran en una producción cada vez más social y un acceso cada vez más restricto y privado de la riqueza, generando una dinámica no solo de desigualdad, sino también de rebeldía y resistencia (Iamamoto, 2003). La profesión sería parte de aquellos mecanismos ideológicos movilizados para identificar los conflictos sociales, existentes o latentes, captar sus núcleos problemáticos y actuar sobre los mismos, de 
modo tal de incidir en los aspectos objetivos y subjetivos de los individuos y grupos, incidiendo en sus modos de ver, actuar y comportarse, de forma tal que adopten determinados modos de vida, acción y pensar.

Es decir, el Trabajo Social sería un complejo ideológico de carácter restricto que aborda un conjunto de problemas sociales que derivan del cotidiano de amplios segmentos de la población, reproduciendo con su accionar intereses de carácter antagónico: tanto la manutención del status quo como la accesibilidad de aquellas conquistas y derechos de las clases subalternas.

Reconocer esto, sin dudas, es una de las claves esenciales para generar una intervención situada y construir estrategias profesionales que permitan ampliar la autonomía relativa con la que cuenta el profesional en la institución y navegar sobre dicha contradicción, pudiendo orientar la intervención a uno de estos intereses antagónicos.

La superación de la demanda institucional, que no supone descartar todas las tareas y acciones que la institución demanda de los profesionales, vuelve esencial una posición teleológica secundaria que supere el reflejo condicionado, como respuesta inmediata entre teoría y práctica, y plantee finalidades profesionales que aspiren al mediano y largo plazo, construyendo las estrategias y tácticas necesarias para su consecución.

Para ello, resulta central considerar que la intervención profesional se constituye en una síntesis de múltiples determinaciones en la que se conjugan los objetivos y relaciones de poder presentes en la institución empleadora, así como las necesidades y objetivos presentes en la población usuaria. Comprender y desandar este aspecto, que en el cotidiano de la intervención se presenta como algo caótico, requiere de un proceso de reconstrucción analítico que apunte a captar tres dimensiones ontológicas que se encuentran articuladas: lo socio-institucional, el subdeterminante popular y lo éticopolítico (Gianna y Mallardi 2011, Gianna 2011).

En primer término, la dimensión socio-institucional expresa el tratamiento general que el Estado da a las manifestaciones de la "cuestión social" y como se presenta en la institución concreta en la que se inserta el profesional. Es decir, si el Estado aborda el conjunto de expresiones de la "cuestión social" mediante un tratamiento que contribuye a parcializarla y fragmentarla, como problemas sociales aislados que no tienen vinculación entre sí (problemas de 
salud, de educación, de vivienda, etc.) y con su causa (la relación social y antagónica entre el capital y el trabajo), esto lleva a que las políticas sociales tengan un aspecto público y privado. Dicho aspecto público remite a que el Estado amplía su faz de actuación y reconoce que mediante un conjunto de reformas pueden atenderse ciertas necesidades demandadas por segmentos de la población, pero, al mismo tiempo, se complementa con una fase privada, que tiende a reproducir el aspecto individual del problema, culpabilizando al individuo de su situación y por no aprovechar las posibilidades que la sociedad le ofrece (Netto, 1997). Estos elementos propios del abordaje que el Estado lleva adelante cuando toma para sí las manifestaciones de la "cuestión social" se expresan en una tendencia que no solo psicologiza y culpabiliza a los individuos, sino que también introduce inducciones comportamentales para que los individuos actúen de determinado modo y no de otro.

Dilucidar cómo esto se presenta en la institución empleadora, requiere de un proceso analítico que debe estar acompañado por una exploración de las finalidades y objetivos de la política social o de la institución empleadora, los recursos asequibles e inasequibles con los que se dispone, los criterios de delimitación de la población usuaria y las relaciones de poder existentes en el seno de la institución.

Sin embargo, esta primera dimensión no determina unívocamente a la profesión, ya que existen otros aspectos que subdeterminan a la misma. Por ello se denomina a la segunda dimensión como subdeterminante popular, en cuanto existe una capacidad objetiva de interpelación e incidencia de la población usuaria en las instancias hegemónicas que intervienen sobre la "cuestión social" y sobre las instituciones que planifican y ejecutan las políticas sociales.

Esta dimensión debe permitir una reconstrucción de las necesidades, intereses y posicionamientos de la población usuaria, en cuanto sujetos colectivos que, con sus acciones y posicionamientos, inciden sobre la intervención profesional y la institución. Pero, además de esto, deben captarse las relaciones existentes entre estos aspectos generales y las situaciones que el profesional aborda desde su intervención cotidianamente.

Finalmente, la dimensión ético-política introduce la cuestión de la articulación de los valores que se objetivan en la intervención profesional y su vinculación con las finalidades y los medios. Más allá de los aspectos contenidos en los códigos de ética, la profesión articula, inclusive desde la pluralidad de 
posiciones, un conjunto de proposiciones teóricas y políticas respecto al modo de concebir a los individuos, las relaciones sociales, la sociedad como un todo, etc. y los valores que la profesión apunta a defender con su actuación profesional, como la democracia, la libertad, la justicia social y cuyo horizonte es la emancipación humana.

Así, la ética se constituye en una herramienta para posicionarse en las instituciones, permitiendo objetivar posicionamientos teórico-políticos que orienten el accionar profesional a la consecución y materialización de dichos valores en las instituciones en las que se insertan los trabajadores sociales, articulándose con los proyectos societarios en pugna y en los intereses antagónicos que existen en el seno institucional.

Estas dimensiones, que no aspiran a convertirse en una nueva receta ni en un nuevo esquema metodológico a priori, permiten introducir, en el seno de la actuación profesional, estrategias de intervención orientada por finalidades que no solo incorporan lo que las instituciones demandan de los profesionales, sino también las reivindicaciones de la población usuaria y los valores éticos que se materializan en prácticas teórico-políticas de los profesionales. Esta finalidad profesional debe estar articulada con los aspectos táctico-operativos, con aquellos movimientos parciales que el profesional realiza, de manera subordinada a la estrategia, para alcanzar la finalidad planteada, las cuales, solo pueden ser determinados en una situación concreta y en un momento histórico concreto.

\section{Consideraciones finales}

l 1 recorrido hecho con este artículo ha tenido una doble finalidad: la 1 primera, dilucidar, mediante la obra de Marx y de Lukács, cuál es la naturaleza del Trabajo Social y, en segundo lugar, analizar cómo la comprensión del primer aspecto tiene consecuencias teóricas y políticas en el modo de concebir y pensar los procesos de intervención profesional.

Si respecto al primero de estos objetivos se vislumbró que el Trabajo Social, por el lugar objetivo que ocupa en la división social y técnica del trabajo, sería un complejo social ideológico, vale la pena destacar que este cumple una función ideológica restricta, ligada al proceso de reproducción y/o transformación de las situaciones problemáticas que emergen en el cotidiano. No obstante, la profesión también puede introducir elementos críticos en las instituciones y problematizar la demanda institucional, permitiendo ampliar la misma e 
incorporar nuevas reivindicaciones y necesidades de la población usuaria. Este accionar, que no es eminentemente práctico, requiere de la producción y apropiación de una masa de conocimientos teóricos que la profesión elabora, permitiendo introducir en el seno del Trabajo Social una reflexión de los componentes esenciales de la sociabilidad humana y los problemas presentes en su particularidad socio-histórica en el capitalismo. Es este aspecto el que vincula al Trabajo Social con los complejos ideológicos puros.

Finalmente, se sostiene que esta vía teórica contribuye a la comprensión de las mediaciones entre el significado social de la profesión y los elementos particulares presentes en su intervención. Profundizar estos aspectos es una de las claves teóricas para avanzar en la construcción de un Trabajo Social crítico que dilucide los límites y posibilidades de la profesión y genere procesos de intervención situados que apunten a superar la inmediatez y construyan, junto a la población usuaria, procesos transformadores.

\section{BIBLIOGRAFÍA}

Gianna, S. (2011). Vida cotidiana y Trabajo Social: límites y posibilidades en la construcción de estrategias de intervención profesional. Revista Cátedra Paralela, № 8, 48-68.

Gianna, S. \& Mallardi, M. (2011). El Trabajo Social como complejo social. Aproximación a los fundamentos de los procesos de intervención profesional. Revista Debate e Sociedade, V. 1, N 1, 22-39.

Iamamoto, M. (1997). Servicio social y división del trabajo. Brasil; Cortez Editora.

Iamamoto, M. (2003). Servicio social en la contemporaneidad. Brasil: Cortez Editora.

Karsz, S. (2007). Problematizar el Trabajo Social: definición, figuras, clínica. España: Gedisa Editorial.

Lessa, S. (2007). Serviço social e trabalho: porque o serviço social não é trabalho, Brasil: EDUFAL.

Lukács, G. (1981). Per l`ontologia dell`essere sociale. Italia: Riuniti,

Lukács, G. (2004). Ontología del ser social. El trabajo. Argentina: Ediciones Herramienta.

Marx, K. (2002). El capital. Argentina: Siglo XXI Editores.

Marx, K. (2004). Introducción general a la crítica de la economía política /1857, Argentina: Siglo XXI Editores.

Marx K., Engels F. (1959). La ideología alemana, Uruguay: Pueblos Unidos.

Netto, J. P. (1997). Capitalismo monopolista y servicio social, Brasil: Cortez Editora.

Palobra No. 14. Agosto de 2014 